\title{
Chemotherapy Induced Amenorrhea in Women Treated with Chemotherapy for Breast Carcinoma in Yalgado Ouédraogo Teaching Hospital in Ouagadougou, Burkina Faso
}

\author{
Augustin Tozoula Bambara ${ }^{1}$, Hyacinthe Zamané2, Yobi Alexis Sawadogo², \\ Hierrhum Aboubacar Bambara1, Awa Mien1, Nayi Zongo', \\ Abdoul Azize Diallo ${ }^{2}$, Ali Ouédraogo ${ }^{2}$, Si Simon Traoré ${ }^{1}$
}

${ }^{1}$ General and Digestive Surgery of Yalgado Ouedraogo Teaching Hospital, Ouagadougou, Burkina Faso ${ }^{2}$ Obstetrics and Gynecology of Yalgado Ouedraogo Teaching Hospital, Ouagadougou, Burkina Faso Email: `tozoula@yahoo.fr, zamanehyacinthe@gmail.com, sawalexis@yahoo.fr, boubabambara@hotmail.com, mienawab@yahoo.fr, colsa3@yahoo.fr, dialloazize@yahoo.fr, doc_aliouedraogo@yahoo.fr, sidolo-touba@yahoo.fr

How to cite this paper: Bambara, A.T., Zamané, H., Sawadogo, Y.A., Bambara, H.A., Mien, A., Zongo, N., Diallo, A.A., Ouédraogo, A. and Traoré, S.S. (2017) Chemotherapy Induced Amenorrhea in Women Treated with Chemotherapy for Breast Carcinoma in Yalgado Ouédraogo Teaching Hospital in Ouagadougou, Burkina Faso. Open Journal of Obstetrics and Gynecology, 7, 129-138.

http://dx.doi.org/10.4236/ojog.2017.71014

Received: December 31, 2016

Accepted: January 15, 2017

Published: January 18, 2017

Copyright $\odot 2017$ by authors and Scientific Research Publishing Inc. This work is licensed under the Creative Commons Attribution International License (CC BY 4.0).

http://creativecommons.org/licenses/by/4.0/ (c) (i) Open Access

\section{Abstract}

Background: We conducted this study to identify factors associated with the onset and reversibility of chemotherapy-induced amenorrhea in Yalgado Ouédraogo Teaching Hospital of Ouagadougou. Methods: A historical cohort study was performed and covered the period from 1 January 2014 to 31 July 2015 . No menopausal patients managed for a histologically confirmed breast carcinoma and having benefited from chemotherapy were included in the study. Logistic regression analysis was used to determine the factors associated with the occurrence of chemotherapyinduced amenorrhea as well as its reversibility. Results: Seventy patients were included. The mean age was 38.5 years. Thirteen patients were obese and 19 (40.4\%) had their menarche after age of 15 years. Adjuvant chemotherapy was administered to 31 patients while 12 had received neoadjuvant chemotherapy. Sequential chemotherapy with an anthracycline and a taxanetherapeutic protocol was the most used. Forty-seven patients had a chemotherapy-induced amenorrhea. The risk of having a chemotherapy-induced amenorrhea increases by $25 \%$ for each additional year of age at diagnosis of cancer $(p=0.0001)$. Obesity and menarche after age 15 were found to be protective factors. After adjusting these variables together, age, obesity, and age at menarche were factors independently associated with the occurrence of the chemotherapy-induced amenorrhea. The reversibility was effective in 11 cases $(37.9 \%)$ and especially concerned patients younger than 40 years $(p=0.03)$. Conclusion: Age is the primary risk factor. Reliable markers of ovarian function need to be developed to better select fertility conservation protocols. 


\section{Keywords}

Amenorrhea, Chemotherapy, Breast Carcinoma

\section{Introduction}

Breast cancer is the leading cancer in women worldwide. Almost a third (32.7\%) of patients affected by this disease are under 50 years [1], so probably no menopausal. Chemotherapy which is one of the main therapeutic means is a source of gonadal toxicity and may be associated with a significant risk of transient or permanent alteration of the ovarian function [2]. The loss of fertility, which is a consequence of ovarian function suppression, often concerns patients of childbearing age with breast cancer [3]. Many studies have focused on chemotherapy-induced amenorrhea to assess the determinant factors. The main risk factors are age, chemotherapy protocols and cumulative doses [4] [5]. Other factors such as anthropometric parameters (weight, height), and lifestyle (smoking) were incriminated [6]. The risk of loss of fertility in women treated for breast cancer is important because of the direct effect of cytotoxic drugs on ovarian function and pregnancy proscriptions imposed by the long duration of treatment [7]. These patients expressed the need for information on fertility preservation strategies and their chances of subsequent procreation. We conducted this study to identify factors associated with the onset and reversibility of chemotherapy-induced amenorrhea in our context, to help improve the quality of life of patients by providing answers to the questions related to chemotherapy-induced amenorrhea.

\section{Patients and Methods}

The study took place in the departments of General and Digestive Surgery and Obstetrics and Gynecology of the Yalgado Ouédraogo Teaching Hospital in Ouagadougou. It was a historical cohort study of patients followed between 1 January 2014 and 31 July 2015 for a histologically confirmed breast carcinoma. We included non-menopausal women who received at least 4 cycles of chemotherapy according to either of the following procedures: adjuvant, neoadjuvant or "perioperative". We have designated "perioperative" the strategy of administering 3 cycles of chemotherapy before surgery and followed by 3 more cycles after. Patients who had amenorrhea prior to onset of chemotherapy, patients who did not receive the expected number of cycles, and patients who did not consent to participate in the study were not included.

The chemotherapy regimens used were as follows: 4 or 6 FAC (5-fluorouracil 600 $\mathrm{mg} / \mathrm{m}^{2}$, doxorubicin $60 \mathrm{mg} / \mathrm{m}^{2}$, cyclophosphamide $600 \mathrm{mg} / \mathrm{m}^{2}$, a cycle every 21 days), 6 FEC (5-fluorouracile: $500 \mathrm{mg} / \mathrm{m}^{2}$, Epirubicin $100 \mathrm{mg} / \mathrm{m}^{2}$, cyclophosphamide $500 \mathrm{mg} / \mathrm{m}^{2}$, every 21-day cycle), 3 FAC-3TXT ( 3 cycles of FAC followed by 3 cycles of docetaxel 100 $\mathrm{mg} / \mathrm{m}$ one every 21-day cycle), 3 FEC-3TXT ( 3 cycles of FEC followed by 3 cycles of docetaxel $100 \mathrm{mg} / \mathrm{m}^{2}$, every 21-day cycle), 4 FAC-4TXT (4 cycles of FAC followed by 4 cycles docetaxel $100 \mathrm{mg} / \mathrm{m}^{2}$, a cycle every 21 days), 4 FEC-4TXT (4 cycles of FEC followed by 4 cycles of docetaxel $100 \mathrm{mg} / \mathrm{m}^{2}$, every 21-day cycle). All the chemotherapies were administered every 21 days. The patients who did not receive the required number 
of cycles were not included.

The variable of interest was secondary amenorrhea, which was defined as any cessation of menses for at least three months after the beginning of chemotherapy in a woman with normal menses previously [8] after ruling out a pregnancy. The time of onset of amenorrhea, its psychological impact and reversibility were considered. Also, other variables such as the modalities of chemotherapy, patient's clinical and para clinical data, sociodemographic characteristics, obstetric and gynecological history, comorbidities, other treatments received during chemotherapy and the desire for pregnancy after chemotherapy have been taken into account. Performans status was measured by the Eastern Collaborative Oncology Group (ECOG) scale. The weight status was described by the Body Mass Index (BMI) defined by the body mass (in $\mathrm{kg}$ ) divided by the square of the body height (in $\mathrm{m}$ ). Patients were classified as follows: Obesity (BMI over 30), Overweight (BMI between 25 and 29.9), normal weight (BMI between 18.5 and 24.9), Slim (BMI less than 18.5).

The characteristics of patients and disease were analyzed by the mean, median and proportion according to cases. The logistic regression analysis was used to identify factors associated with the occurrence of chemotherapy-induced amenorrhea and that of its reversibility. In the model, potential factors associated with chemotherapy-induced amenorrhea were tested in univariate then multivariate analysis using a regressive "manual" procedure. For categorical variables, the groups were compared using a Chi-square's test. Different associations have been described by Odd ratios, confidence intervals, as well as their degree of significance $p$. A significance level of 0.05 was used for all analyzes.

\section{Results}

\subsection{Patient Characteristics}

In all 66 patients were included. The mean age was 38.5 years (SD: 7.1 years) with extremes of 23 and 50 years. Forty-seven (71.2\%) of the patients had presented amenorrhea during their chemotherapy. The mean age of these patients was 41 years (SD: 6 years) and the age group 41 to 45 years was the most represented. Thirty-eight patients (80.9\%) had an ECOG performans status of 1 and 13 were obese (Table 1). Nineteen (40.4\%) had their menarche after age 15 years. Twelve patients were using hormonal contraception before diagnosis of their cancer: 5 took combined oral contraceptives, 5 had an injectable contraception, and two had implants. None of them has continued this contraception during the chemotherapy. Data on the disease and chemotherapy are summarized in Table 2. The invasive ductal carcinoma was the histological type found in all patients. Tumor Scarff Bloom Richardson histological grade 2 (SBR 2) was predominant. Forty-three patients had consulted at stage III. In 4 cases, information on the size of the primary tumor was not available. Adjuvant chemotherapy was administered to 31 patients while 12 had received neoadjuvant chemotherapy. Sequential chemotherapy with an anthracycline and a taxane therapeutic protocol was the most used (59.5\%). Patients received 3 or 4 cycles of anthracycline-based chemotherapy (Doxorubicin or Epirubicin), followed by 3 or 4 cycles of docetaxel. The remaining patients (40.5\%) received 4 or 6 cycles of an anthracycline-based protocol. Hormone based therapy was prescribed in 5 patients who had received hormone receptor analysis by immunohistochemistry. 
Table 1. Patient's characteristics $(n=66)$.

\begin{tabular}{|c|c|c|}
\hline Caracteristics & Numbers of cases & $\%$ of total \\
\hline \multicolumn{3}{|c|}{ Age intervals (years) } \\
\hline $21-25$ & 1 & 2.1 \\
\hline $26-30$ & 2 & 4.2 \\
\hline $31-35$ & 6 & 12.8 \\
\hline $36-40$ & 13 & 27.7 \\
\hline $41-45$ & 14 & 29.8 \\
\hline $46-50$ & 11 & 23.4 \\
\hline \multicolumn{3}{|c|}{ ECOG performance status } \\
\hline ECOG $0^{*}$ & 2 & 4.3 \\
\hline ECOG 1 & 38 & 80.9 \\
\hline ECOG 2 & 4 & 8.5 \\
\hline ECOG 3 & 3 & 6.4 \\
\hline \multicolumn{3}{|l|}{ Body weight } \\
\hline Slim & 1 & 2.1 \\
\hline Normal & 24 & 51.1 \\
\hline Over weight & 9 & 19.1 \\
\hline Obesity & 13 & 27.7 \\
\hline \multicolumn{3}{|c|}{ Age of menarches } \\
\hline$<15$ years & 28 & 59.6 \\
\hline$>15$ years & 19 & 40.4 \\
\hline \multicolumn{3}{|l|}{ Parity } \\
\hline Nulliparous & 3 & 6.4 \\
\hline Primiparous & 8 & 17.0 \\
\hline Pauciparous & 16 & 34.0 \\
\hline Multiparous & 14 & 29.8 \\
\hline High parity & 6 & 12.8 \\
\hline
\end{tabular}

ECOG: Eastern Cooperative Oncology Group.

Table 2. Stages, SBR's score of the disease and chemotherapy regimens.

\begin{tabular}{ccc}
\hline Factors & Numbers of cases & \% of total \\
\hline Stage & 9 & \\
I & 10 & 19.1 \\
II & 43 & 21.3 \\
III & 4 & 65.2 \\
NS & 4.5 \\
\hline
\end{tabular}




\section{Continued}

\begin{tabular}{ccc}
\hline SBR's score & 2 & \\
1 & 31 & 4.3 \\
2 & 10 & 66.0 \\
3 & 4 & 21.3 \\
NS & & 8.5 \\
Modalities & 12 & \\
Neo adjuvante & 31 & 25.5 \\
Adjuvante & 4 & 66.0 \\
Perioperative & & 8.5 \\
Protocols & 12 & \\
6 FAC & 6 & 25.5 \\
4 FAC & 1 & 12.8 \\
6 FEC & 23 & 2.1 \\
3 FAC-3 TXT & 2 & 48.9 \\
4 FAC-4 TXT & 2 & 4.2 \\
3 FAC-2 TXT & 1 & 4.3 \\
4 FEC-4 TXT & & 2.1 \\
\hline
\end{tabular}

SBR: Scarff-Bloom Richardson; NS: Not Specified; FAC: Fluorouracile, Adriamycin, Cyclophosphamide; FEC: Fluorouracile, Epirubicin, Cyclophosphamide; ECOG: Eastern Cooperative Oncology Group.

\subsection{Data on Amenorrhea}

The amenorrhea has occurred after the first treatment cycle in 19 patients (40.4\%), after the second in 12 patients (25.5\%), after the third in 11 patients (23.4\%), after fourth in 4 patients and after the sixth treatment in a patient. Table 3 and Table 4 summarize the association between the chemotherapy-induced amenorrhea and different factors. In univariate analysis, age greater than 40 years was a risk factor for onset of chemotherapy-induced amenorrhea. The risk of occurrence of chemotherapy-induced amenorrhea increased by $25 \%$ for each additional year of age at diagnosis of cancer $(p<0.01)$. Obesity and menarche after age 15 were protective factors: odds ratio $(\mathrm{OR})=0.07$ ( $p<$ $0.01)$ and $0.17(p=0.007)$, respectively. After adjusting the variables together, age, obesity, were factors independently associated with the occurrence of the chemotherapy-induced amenorrhea: odds ratio $(\mathrm{OR})=6.62(p=0.001)$ and $0.07(p<0.01)$, respectively. The reversibility of amenorrhea was noted in 29 patients. It was effective in 11 cases $(37.9 \%)$ and especially concerned patients younger than 40 years $(58.8 \% ; p=$ 0.03). Twelve patients (25.5\%) had expressed the desire to conceive after their cancer treatment while 21 have claimed to be concerned about the amenorrhea.

\section{Discussion}

The small sample size resulted in weak statistical power of the tests performed and the deterioration of approximations. Many patients were not included because they have not received the required number of cycle due to the lack of financial resources. In 
Table 3. Factors associated with chemotherapy-induced amenorrhea (univariate analysis).

\begin{tabular}{|c|c|c|c|}
\hline Factors & OR & CI95\% & $p$ value \\
\hline \multicolumn{4}{|l|}{ Age } \\
\hline$\leq 40$ years & 1 & & \\
\hline$>40$ years & 6.62 & {$[1.89 ; 23.17]$} & 0.003 \\
\hline \multicolumn{4}{|l|}{ Menarches } \\
\hline$<15$ years & 1 & & \\
\hline$\geq 15$ years & 0.18 & {$[0.05 ; 0.63]$} & 0.007 \\
\hline \multicolumn{4}{|l|}{ Obesity } \\
\hline No & 1 & & \\
\hline Yes & 0.07 & {$[0.02 ; 0.29]$} & $<0.01$ \\
\hline \multicolumn{4}{|l|}{ Sequential ${ }^{*}$} \\
\hline No & 1 & & \\
\hline Yes & 1.64 & {$[0.56 ; 4.78]$} & 0.37 \\
\hline \multicolumn{4}{|l|}{ Parity } \\
\hline Nulliparous & 1 & & \\
\hline Primiparous & 5.33 & {$[0.62 ; 46.0]$} & 0.13 \\
\hline Pauciparous & 3.05 & {$[0.53 ; 17.4]$} & 0.21 \\
\hline Multiparous & 3,11 & {$[0.53 ; 18.4]$} & 0.21 \\
\hline \multicolumn{4}{|l|}{ Modalities } \\
\hline Adjuvante & 1 & & \\
\hline Neoadjuvante & 0.3 & {$[0.09 ; 0.99]$} & 0.04 \\
\hline Interval & 0.3 & {$[0.05 ; 1.66]$} & 1.17 \\
\hline
\end{tabular}

Sequential: Sequential chemotherapy; OR: Odd Ratio; IC95\%: 95\% confidence interval.

Table 4. Factors associated with chemotherapy-induced amenorrhea (logistic regression model).

\begin{tabular}{|c|c|c|c|c|c|c|}
\hline & \multicolumn{3}{|c|}{ Univariate analysis } & \multicolumn{3}{|c|}{ Multivariate analysis } \\
\hline & OR & IC95\% & $p$ value & OR & IC95\% & $p$ value \\
\hline \multicolumn{7}{|l|}{ Age } \\
\hline$\leq 40$ years & 1 & & & 1 & & \\
\hline$>40$ years & 6.62 & {$[1.89 ; 23.17]$} & 0.003 & 23.88 & {$[3.5 ; 162.4]$} & 0.001 \\
\hline \multicolumn{7}{|l|}{ Menarches } \\
\hline$<15$ years & 1 & & & 1 & & \\
\hline$\geq 15$ years & 0.18 & {$[0.05 ; 0.63]$} & 0.007 & 0.18 & {$[0.02 ; 1.25]$} & 0.08 \\
\hline \multicolumn{7}{|l|}{ Obesity } \\
\hline No & 1 & & & 1 & & \\
\hline Yes & 0.07 & {$[0.02 ; 0.29]$} & 0.0002 & 0.03 & {$[0.00 ; 0.21]$} & $<0.01$ \\
\hline \multicolumn{7}{|l|}{ Sequential ${ }^{*}$} \\
\hline No & 1 & & & 1 & & \\
\hline Yes & 1.64 & {$[0.56 ; 4.78]$} & 0.37 & 0.28 & {$[0.05 ; 1.74]$} & 0.17 \\
\hline
\end{tabular}

Sequential: Sequential chemotherapy; OR: Odd Ratio; IC95\%: 95\% confidence interval. 
addition, the representativeness of our sample is limited by the non-inclusion of patients who have not received chemotherapy because of lack of financial resources and the significant proportion of some missing data on outcome of amenorrhea. Bias related to the retrospective collection of certain data in patients who had already completed their courses of chemotherapy should also be considered. Finally, amenorrhea taken as a parameter of interest in this study is not a reliable reflection of ovarian function suppression, by the way the loss of fertility [9], however it remains the most commonly studied and most worrying complaint for patients wishing to conceive after treatment of their cancer. The definition of chemotherapy-induced amenorrhea varies depending on the study, constituting a limit to the comparison with different studies [10]. Indeed, some authors define the chemotherapy-induced amenorrhea in referring to the end of chemotherapy, while others consider a certain delay from the start of the chemotherapy [4]. We have retained the three-month period by referring to the definition of secondary amenorrhea, which is the absence of menses for more than three months in a woman who has normal menses previously [8]. The variability of the incidence's data reflects the heterogeneity of definitions, characteristics of the populations studied and treatment protocols. Thus, the incidence of chemotherapy-induced amenorrhea varies between $20 \%$ to $61 \%$ in patients under 40 years and $61 \%$ to $97 \%$ in patients over 40 years [10]. Age is unanimously the main risk factor. Most studies have shown that women over 40 years were more likely to present a chemotherapy-induced amenorrhea than women under 40 years regardless of the type of treatment received [4] [11] [12]. This difference in risk was found in our study. In addition, it appears that the risk of developing chemotherapy-induced amenorrhea increases by $25 \%$ for each additional year of age at diagnosis of cancer $(p<0.01)$. Petrek made a similar observation [13]. Obesity was a protective factor for the occurrence of the chemotherapy-induced amenorrhea. This could be explained by the under dosage of medication in relation to the body surface. Indeed, because of the narrow therapeutic index of cytotoxic drugs and the fear of an overdose, the adjustment to the body surface is often put at a ceiling of $2 \mathrm{~m}^{2}$. The blood concentration of the drug would be insufficient to induce a chemotherapy-induced amenorrhea. The pharmacokinetics of drugs changes in obese subjects could be another reason for the low incidence of the chemotherapy-induced amenorrhea in obese people. The relationship between body mass index and the chemotherapyinduced amenorrhea has been little studied. Authors who were interested in this parameter found no association [6] [10]. The impact of the chemotherapy-induced amenorrhea also varies depending on the chemotherapy regimen. The most studied associations in recent years are the alkylating based protocols made up of anthracylines and taxanes. Sequential regimens were also compared to non-sequential patterns. These different treatments are variously associated with the chemotherapy-induced amenorrhea. Interpretation of the results of the literature is made difficult by the heterogeneity of methodologies and study populations. Alkylating drugs however, have been described as the most gonadotoxic agents due to their independent mechanism of action on the phases of the cell cycle [5]. In our study, all the chemotherapies were administered every 21 days. The administered taxane was Docetaxel. The weekly Paclitaxel was not prescribed because of high cost and unavailability of this drug. We found no 
association between the type of chemotherapy and the chemotherapy-induced amenorrhea. Cyclophosphamide, which is the most used alkylating drug in breast cancer treatment, was administered to all patients in our series. Unfortunately, we do not have a control group to describe the degree of risk attributable to the drug. Twelve patients were using hormonal contraceptives before diagnosis of their cancer. Four patients were still under hormonal contraception at diagnosis. These contraceptives have been stopped after diagnosis. A non-hormonal contraceptive method has been proposed to patients who wanted to continue contraception.

Gonadal toxicity of chemotherapy is achieved by a decrease of follicular reserve in premenopausal patients. The reduction of the ovarian reserve will result in a decrease in fertility manifested as amenorrhea which is a poor indicator [14]. This amenorrhea may be transient or permanent, leading to early menopause. We speak of chemotherapyinduced early menopause after a period of 12 months of amenorrhea [10], although it is recognized that the return of menses can sometimes be beyond that period. In the NSABP B-30 trial, resumption of menses occurred within 24 months in $45.3 \%$ of patients aged under $40,10.9 \%$ of those aged $40-50$ and in $3.2 \%$ of patients aged over 50 [15]. In our study, the chemotherapy-induced amenorrhea was transient in about 38\% of cases after 4 to 8 months of amenorrhea. The reversibility of amenorrhea was mainly observed in patients under 40 years. However, the follow up period was not enough for assessing its reversibility. A reproductive desire was expressed by $25.5 \%$ of patients who presented a chemotherapy-induced amenorrhea. This reflects the challenge of preserving fertility in these young patients. Two main avenues are being explored, either the protection of ovarian function or the medically assisted reproduction [14]. The protecttion of ovarian function requires the choice of the least gonadotoxic treatment protocol for equivalent effectiveness and the selection of patients who would derive a real benefit from these treatments. The GnRH agonists administered during chemotherapy, have a protective effect of ovarian reserve through a quiescence of the ovaries [14]. Data from the literature does not agree on this rational. Ovarian, oocyte and embryo cryopreservation techniques are still experimented. In our study context characterized by delayed diagnosis, lack of technical setting and precariousness conditions, the challenges associated with poor prognosis in breast cancer outweigh the preservation of patient's fertility. An interval of 2 to 3 years after treatment is recommended for conception [16]; patients who achieve the recommended timeline without recurrence are rare in Ouagadougou.

\section{Conclusion}

The chemotherapy-induced amenorrhea is a frequent complaint in young women treated for cancer. Age is the primary risk factor. The risk attributed to obesity may be related to variations pharmacokinetics. The return of menses, also related to age, is not synonymous with fertility. Reliable markers of ovarian function need to be developed to better select fertility conservation protocols.

\section{References}

[1] Ferlay, J., Soerjomataram, I., Dikshit, R., Eser, S., Mathers, C., Rebelo, M., et al. (2015) 
Cancer Incidence and Mortality Worldwide: Sources, Methods and Major Patterns in GLOBOCAN 2012. International Journal of Cancer, 136, E359-E386. https://doi.org/10.1002/ijc.29210

[2] Blumenfeld, Z. (2012) Chemotherapy and Fertility. Best Practice \& Research Clinical Obstetrics \& Gynaecology, 26, 379-390. https://doi.org/10.1016/j.bpobgyn.2011.11.008

[3] Ruddy, K.J., Gelber, S.I., Tamimi, R.M., Ginsburg, E.S., Schapira, L., Come, S.E., et al. (2014) Prospective Study of Fertility Concerns and Preservation Strategies in Young Women with Breast Cancer. Journal of Clinical Oncology, 32, 1151-1156. https://doi.org/10.1200/JCO.2013.52.8877

[4] Zavos, A. and Valachis, A. (2016) Risk of Chemotherapy-Induced Amenorrhea in Patients with Breast Cancer: A Systematic Review and Meta-Analysis. Acta Oncologica, 55, 664-670. https://doi.org/10.3109/0284186X.2016.1155738

[5] Oktay, K. and Sönmezer, M. (2008) Chemotherapy and Amenorrhea: Risks and Treatment Options. Current Opinion in Obstetrics and Gynecology, 20, 408-415. https://doi.org/10.1097/GCO.0b013e328307ebad

[6] Abusief, M.E., Missmer, S.A., Ginsburg, E.S., Weeks, J.C. and Partridge, A.H. (2012) Relationship between Reproductive History, Anthropometrics, Lifestyle Factors, and the Likelihood of Persistent Chemotherapy-Related Amenorrhea in Women with Premenopausal Breast Cancer. Fertility and Sterility, 97, 154-159. https://doi.org/10.1016/j.fertnstert.2011.10.005

[7] Hickey, M., Peate, M., Saunders, C.M. and Friedlander, M. (2009) Breast Cancer in Young Women and Its Impact on Reproductive Function. Human Reproduction Update, 15, 323339. https://doi.org/10.1093/humupd/dmn064

[8] Roberts-Wilson, T.K., Spencer, J.B. and Fantz, C.R. (2013) Using an Algorithmic Approach to Secondary Amenorrhea: Avoiding Diagnostic Error. Clinica Chimica Acta, 423, 56-61. https://doi.org/10.1016/j.cca.2013.04.007

[9] Green, D.M., Kawashima, T., Stovall, M., Leisenring, W., Sklar, C.A., Mertens, A.C., et al. (2009) Fertility of Female Survivors of Childhood Cancer: A Report from the Childhood Cancer Survivor Study. Journal of Clinical Oncology, 27, 2677-2685. https://doi.org/10.1200/JCO.2008.20.1541

[10] Liedtke, C. and Kiesel, L. (2012) Chemotherapy-Induced Amenorrhea-An Update. Geburtshilfe Frauenheilkunde, 72, 809-818. https://doi.org/10.1055/s-0032-1315361

[11] Zhou, W.B., Yin, H., Liu, X.A., Zha, X.M., Chen, L., Dai, J.C., et al. (2010) Incidence of Chemotherapy-Induced Amenorrhea Associated with Epirubicin, Docetaxel and Navelbine in Younger Breast Cancer Patients. BMC Cancer, 10, 281-286. https://doi.org/10.1186/1471-2407-10-281

[12] Walshe, J.M., Denduluri, N. and Swain, S.M. (2006) Amenorrhea in Premenopausal Women after Adjuvant Chemotherapy for Breast Cancer. Journal of Clinical Oncology, 24, 57695779. https://doi.org/10.1200/JCO.2006.07.2793

[13] Petrek, J.A., Naughton, M.J., Case, L.D., Paskett, E.D., Naftalis, E.Z., Singletary, S.E., et al. (2006) Incidence, Time Course, and Determinants of Menstrual Bleeding after Breast Cancer Treatment: A Prospective Study. Journal of Clinical Oncology, 24, 1045-1051. https://doi.org/10.1200/JCO.2005.03.3969

[14] Basille, C., Torre, A., Grynberg, M., Gallot, V., Frydman, R. And Fanchin, R. (2010) Mise au point: Traitements anticancéreux et réserve ovarienne. Journal de Gynécologie Obstétrique et Biologie de la Reproduction, 39, 433-443. https://doi.org/10.1016/j.jgyn.2010.05.012

[15] Swain, S.M., Land, S.R., Ritter, M.W., Costantino, J.P., Cecchini, R.S., Mamounas, E.P., et al. (2009) Amenorrhea in Premenopausal Women on the Doxorubicin-and-Cyclophosphamide-Followed-by-Docetaxel Arm of NSABP B-30 Trial. Breast Cancer Research and 
Treatment, 113, 315-320. https://doi.org/10.1007/s10549-008-9937-0

[16] Helewa, M., Levesque, P., Provencher, D., Lea, R.H., Rosolowich, V. and Shapiro, H.M. (2002) Breast Cancer, Pregnancy, and Breastfeeding. Journal of Obstetrics and Gynaecology Canada, 24, 164-180. https://doi.org/10.1016/S1701-2163(16)30298-5

Submit or recommend next manuscript to SCIRP and we will provide best service for you:

Accepting pre-submission inquiries through Email, Facebook, LinkedIn, Twitter, etc. A wide selection of journals (inclusive of 9 subjects, more than 200 journals) Providing 24-hour high-quality service User-friendly online submission system Fair and swift peer-review system Efficient typesetting and proofreading procedure Display of the result of downloads and visits, as well as the number of cited articles Maximum dissemination of your research work

Submit your manuscript at: http://papersubmission.scirp.org/ Or contact ojog@scirp.org 